\title{
Design of Buick V6 Electronic-controlled Engine Simulation Experiment Bench
}

\author{
Wenzi GONG \\ College of Automobile Technology, Wuxi Vocational Institute of Commerce, Wuxi, Jiangsu, 214153, \\ China \\ email: gongwenzi1968@sina.com
}

Key words: Simulation; Electronic controlled engine; Experiment bench; Work process; Design

\begin{abstract}
A simulated electronic-controlled engine experiment bench was introduced. The experiment bench is on the basis of Buick V6 electronic controlled engine, which mechanical system is removed, electrical components are kept and a set of systematically complete automobile engine electronic control system with normal functions is built up. The bench structure is simple, temperature sensor signals can be simulated through a variable resistor and the working process is displayed using light bulbs by virtue of executive components such as injector and oil pump, so that the bench's working process is visual and direct and the operation is more convenient. The bench in use is safe, environmental protection and economical, and key positions are equipped with measuring terminals, convenient to detect and also beneficial to carrying out practical teaching. The bench can be developed by school independently, in order to improve the scientific and technological innovation capacity of teachers and students.

A combination of electronic technology and automobile technology has formed a new technology, namely automobile electronic control technology [1]. In order to solve the three problems, automobile safety, pollution and energy saving, automobile electronic control technologies, especially automobile engine electronic control technologies have been rapidly developed and constantly improved [2]. The objective of personnel cultivation of automobile specialties in the vocational colleges is to cultivate high-quality and skilled automobile after-sale technical service personnel. The theoretical and practical teaching of the automobile engine electronic control technology as a core curriculum of automobile specialty in higher vocational colleges is more and more attached importance to by vocational colleges, and it is an important subject for teaching instrument manufacturers and vocational colleges to develop safe, environmental protection and energy saving automobile electronic control engine experiment benches. The applications of simulation experiment bench as a current hot spot and direction of development of experimental equipment are of very important value in terms of automobile electronic control engine experiment bench.
\end{abstract}

\section{Overall Scheme Of The Experiment Bench}

This experiment bench takes the typical car GM Buick V6 electronic controlled engine as the prototype, only the electronic control system and part of its mechanical system are kept, and the electronic control system includes sensor, ECU and actuator; the kept mechanical systems includes accelerator pedal and stay wire, crankshaft timing gear, 7X and 24X crankshaft (timing) signal teeth, toothed belt, camshaft timing gear, and camshaft (timing) signal teeth [3]. Such different components are integrated into an experiment bench, and the components of the electronic controlled system are connected through original wire hardness to build a systematically complete automobile engine electronic control system with normal functions, and the electronic control system can simulate normal running modes, such as starting, idling and acceleration. The whole system has small volume, low cost, simple structure, convenient detection and other strengths [4].

As shown, this experiment bench consists of a slide rheostat 1, storage battery 2, DC motor 3, ignition switch 4, normally open relay 5, exhaust gas recirculation valve with position sensor (6), idle speed control valve 7, oil pump relay 8 , oil pump working indicator light 9, 4-cylinder spark plug 10, 1- cylinder spark plug 11, 5-cylinder spark plug 12, 2- cylinder spark plug 13, 6-cylinder 
spark plug 14, 3- cylinder spark plug 15, 7X magnetoelectric crankshaft position sensor 16, air intake pressure sensor 16, water temperature sensor 18, air intake temperature sensor 19, $24 \mathrm{X}$ Hall crankshaft position sensor 20, Hall camshaft position sensor 21, oil level sensor 22, knock sensor 23, throttle position sensor 24, 1-cylinder injector indicator light 25, 2-cylinder injector indicator light 26, 3-cylinder injector indicator light 27, 4-cylinder injector indicator light 28, 5- cylinder injector indicator light 29, 6-cylinder injector indicator light 30, air flow sensor 31, charcoal canister electromagnetic valve indicator light 32, oxygen sensor 33, measuring terminal 34, axial flow fan 35, power control module PCM, and ignition control assembly [5].

DC motor 3 is driven by homemade crankshaft timing gear and $7 \mathrm{X}$ and $24 \mathrm{X}$ crankshaft signal teeth, 7X crankshaft signal tooth is provided with engine speed signal and crankshaft position signal via the ignition control assembly of $7 \mathrm{X}$ magnetoelectric crankshaft position sensor 16, and $24 \mathrm{X}$ crankshaft signal tooth is provided with engine speed signal and crankshaft position signal to the power control module PCM by 24X Hall crankshaft position sensor 20 (6); at the same time, the crankshaft timing gear is rotated by the toothed belt driving the camshaft timing gear and camshaft signal tooth, and the camshaft signal tooth is provided with camshaft position signal to the power control module PCM through Hall camshaft position sensor 21 [7]. The slide rheostat 1 is arranged below the accelerator pedal, and links with the accelerator pedal, that is, when stepping down the accelerator pedal, the resistance is reduced, and on the contrary, its resistance value increases, so it is used to control the speed of DC motor 3 (or engine). The axial flow fan 35 parallel to the DC motor 3 is positioned on the air inlet channel at the rear of the throttle body to simulate the suction process of the piston at the time of downward intake stroke, air flow signal is provided to the power control module PCM through the air flow sensor 31, and air inlet pressure signal is also provided to the power control module PCM through the intake pressure sensor 17 [8]. The air flow rate, air inlet pressure, accelerator pedal position and engine speed increase or decrease synchronously, the lower the accelerator pedal position, the greater the air flow rate, air inlet pressure and engine speed.

Water temperature sensor 18, air intake temperature sensor 19, and oil level sensor 22 can be replaced with a variable resistor with appropriate resistance value range, and a different resistance value can simulate the corresponding signal (9);1-cylinder injector indicator light 25, 2-cylinder injector indicator light 26, 3-cylinder injector indicator light 27, 4-cylinder injector indicator light 28, 5-cylinder injector indicator light 29, and 6-cylinder injector indicator light 30 simulate the working process of fuel injector, when the engine rotates, the injector indicator lights are on intermittently [10], when the light is on, it is in the injection status; the charcoal canister electromagnetic valve indicator light 32 simulates the working state of the charcoal canister electromagnetic valve, and the charcoal canister light electromagnetic valve is open when the light is on; the oil pump working indicator light 9 simulates the working state of the electric oil pump, and the oil pump works when the light is on (2).

\section{Control Function And Working Process Of The Experiment Bench}

As shown, this experiment bench based on the template of Buick V6 engine can show the working process of automobile engine electronic control system in an intuitive and marked manner. It is very convenient to debug and test this equipment, and it is safe, economic and environmental protection. When the ignition switch 4 is closed, each control unit is provided with power supply, and the main control functions are as follows.

Working Principle Of The Ignition System. The functions of the four wires used to connect the ignition control assembly with the power control module PCM are as follows.

(1) $3 \mathrm{X}$ reference signal high $(3 \mathrm{X}+)$ : pulse signal. $7 \mathrm{X}$ magnetoelectric crankshaft position sensor 16 sends engine speed and crankshaft position signal to the ignition control assembly, the ignition control assembly generates $3 \mathrm{X}$ reference signal and sends to the power control module PCM, and the PCM uses this signal to calculate crankshaft position and engine speed, and it is used to trigger the injector (11).

(2) 3X reference signal low (3X-): this circuit is grounded and bonded by the ignition control assembly. 
(3) Bypass control circuit (bypass): at the time of initial starting, the ignition control assembly controls ignition. The PCM provides $5 \mathrm{~V}$ voltage to the ignition control assembly through the by-pass control circuit, so that the ignition control assembly controls ignition (12).

(4) Ignition control circuit (IC): pulse signal. After starting the engine, the power control module PCM controls ignition, and the ignition control assembly is triggered by the circuit [13].

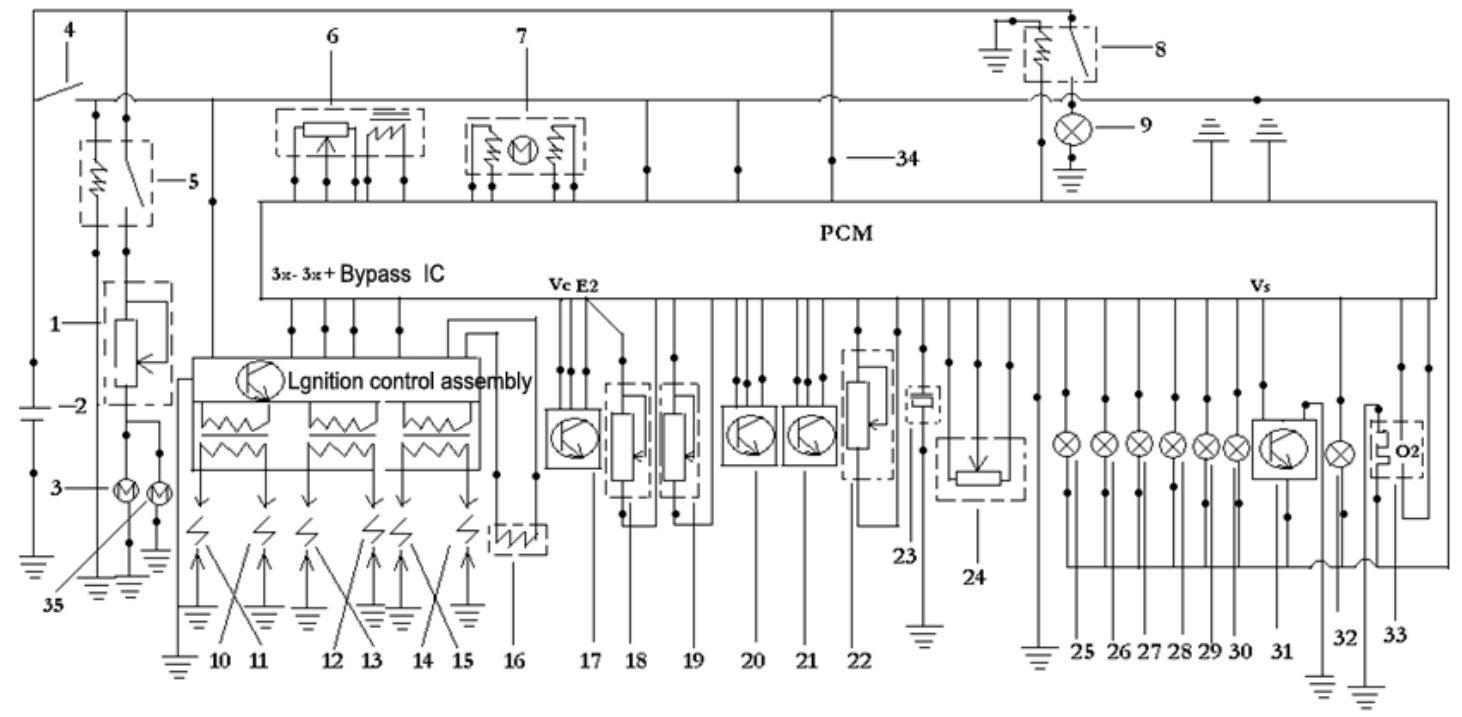

Control principle diagram

1 - slide rheostat 2- storage battery 3 - DC motor 4-ignition switch 5 - normally open relay 6 - exhaust gas recirculation valve with position sensor 7 - idle speed control valve 8 - oil pump relay 9 - oil pump working indicator light 10 -4-cylinder spark plug 11 - 1 - cylinder spark plug 12 - 5-cylinder spark plug 13 - 2-cylinder spark plug 14 - 6-cylinder spark plug 15 - 3-cylinder spark plug 16 - 7X magnetoelectric crankshaft position sensor 17 - intake pressure sensor 18 - water temperature sensor 19 - air intake temperature sensor 20 - 24X Hall crankshaft position sensor 21 - Hall camshaft position sensor 22 - oil level sensor 23 - knock sensor 24 - throttle position sensor 25 - 1-cylinder injector indicator light 26 2-cylinder injector indicator light 27 -3-cylinder injector indicator light 28 -4-cylinder injector indicator light 29 - 5-cylinder injector indicator light 30 - 6-cylinder injector indicator light 31 - air flow sensor 32 - charcoal canister electromagnetic valve indicator light 33 - oxygen sensor 34 - measuring terminal 35 - axial flow fan

Working Process Of The Experiment Bench. When the ignition switch 4 is closed, the switch contact of the normally open relay 5 is pulled up, the DC motor3 with axial flow fan 35 runs with a certain speed according to the accelerator pedal's position, 7X magnetoelectric crankshaft position sensor 16 provides 24X Hall ignition control assembly 20 and $24 \mathrm{X}$ crankshaft position sensor provides the power control module PCM with position signal and crankshaft position signal, and the Hall crankshaft camshaft position sensor 21 provides the power control module PCM with camshaft position signal (14); the axial flow fan 35 provides air flow to the air flow sensor 31 and air intake pressure sensor 17, the air flow sensor 31 converts the air intake flow signal into electrical signal, the air inlet pressure 17 converts the air inlet pressure sensor signal into electrical signal and transmits to the power control module PCM, the air inlet pressure signal verifies mutually with air flow signal and corrects, and when one of the signals fails, the other can be while the corresponding fault code is formed; the water temperature sensor 18, the air intake temperature sensor 19, and oil level sensor 22 according to the adjusted resistance provide the power control module PCM with water temperature signal, air inlet temperature and fuel position signal; the throttle position sensor 24 according to the accelerator pedal position provides the power control module PCM with throttle position signal. The power control module PCM according to each sensor's signal is used through calculation, analysis and processing to determine an optimal fuel injection quantity, injection time and ignition time (15), to control the working state of each cylinder injector indicator light, each cylinder spark plug, ignition control assembly, idle speed control valve 7, exhaust gas recirculation 
valve 6 , oil pump working indicator light 9 , charcoal canister electromagnetic valve indicator light 32 and other executing elements, so that the fuel injection and ignition frequency synchronize with the engine speed.

The Measuring Terminals Are Used To Test Voltage. resistance, waveform and various other parameters, convenient for fault judgment and detection and meeting teaching needs.

\section{Conclusions}

Traditional teaching methods, teaching means and teaching equipment have not by far met the requirements of modern teaching, but there are restrictions on costs, places, number of teachers and students and teaching time if using the mode of vehicle object teaching. In view of the "automobile engine electronic control technology" course, on the basis of Buick V6 electronic-controlled engine as a template, we researched and developed an electronic control engine simulation experiment bench suitable for vocational education and vocational training. The experiment bench has low production costs and a simple structure, and is safe, environmental protection and economical when running; bulb as an actuator enables the entire process to be more visual and direct, enhancing the teaching effect; some sensors can be simulated by variable resistor, so that the signal changes become more direct and convenient, which is also convenient for teachers' teaching and student learning. The bench can also be developed, designed and produced by the students under teacher's guidance in the form of innovation project, to improve the students' ability of scientific and technological innovation.

\section{References}

[1] Zhang Xizhen. Automobile engine electronic control technology [M]. Beijing: China Machine Press, 2009.

[2] Chen Banglu, Gong Wenzi. Automobile engine electronic control system [M]. Beijing: National Defense Industry Press, 2012

[3] Cao Limin. Maintenance manual of Buick Regal cars [M]. Beijing: China Machine Press, 2004

[4] Gong Wen. Design of the experimental bench for simulation of working process [J]. Laboratory research and exploration, 2012, 31 (1): 204-206.

[5] Zhang Fengshan. Structure and maintenance of Shanghai Buick Car [M]. Beijing: Jindun press, 2001.

[6] Li Baihua. Automobile engine electronic control technology [M]. Beijing: Posts and Telecom Press, 2009.

[7] Wang Suishuang. Principle and maintenance of automobile electronic control system (electronic fuel injection engine) [M]. Beijing: Beijing Institute of Technology Press, 2000.

[8] Wang Xiuhong, Tian Youwei. Automobile engine electronic control technology [M]. Dalian: Dalian University of Technology Press, 2007.

[9] Chen Gaolu. Testing and maintenance worksheet of automobile engine control system [M]. Beijing: China Communications Press, 2007.

[10] An Zongquan, Tian Youwei Automobile engine electronic control system testing [M]. Beijing: Posts and Telecom Press, 2009

[11] Sun Haibo. Automobile engine overhaul [M]. Beijing: Posts and Telecom Press, 2009

[12] Zhang Falong. Automobile engine electronic control technology and overhaul [M]. Beijing: Electronic Industry Press, 2007

[13] Wang Chengliang. Automobile engine electronic control system technology and overhaul [M]. Beijing: China Machine Press, 2009 
[14] Zhu Tao. Automobile engine electronic control technology [M]. Beijing: Chemical Industry Press, 2010

[15] Guo Ruilian. Principle and fault analysis of automobile electronic control system [M]. Beijing: Beijing University of Technology Press, 2010 